\title{
The incidence and risk factors for allogenic blood transfusion in total knee and hip arthroplasty
}

\author{
Kai Song ${ }^{1,2+}$, Pin Pan ${ }^{1,2+}$, Yao Yao ${ }^{1,2}$, Tao Jiang ${ }^{1,2}$ and Qing Jiang ${ }^{1,2^{*}}$ (D)
}

\begin{abstract}
Background: Excessive blood loss in total joint arthroplasty (TJA) usually leads to an allogenic blood transfusion, which may cause adverse outcomes, prolonged length of hospitalization, and increased costs. The purpose of this study was to determine the incidence and risk factors for intraoperative and postoperative allogenic transfusion in patients undergoing primary unilateral total knee and hip arthroplasty (TKA and THA).

Methods: We conducted a retrospective study and enrolled consecutive patients undergoing primary unilateral TKA and THA at our institution between January 2010 and July $2014(n=1534)$. Information about allogenic transfusion was collected from medical records to determine the incidence. We performed univariate analysis and multivariate logistic regression analysis to identify the independent risk factors.

Results: Total, intraoperative, and postoperative transfusion rates were $17.9 \%, 7.9 \%$, and $11.3 \%$, respectively. The preoperative lower level of hemoglobin $(\mathrm{Hb})(P<0.001)$ and increased amount of intraoperative blood loss $(P<0.001)$ were independently associated with transfusion in TKA. The independent risk factors for transfusion in THA were female $(P=0.023)$, preoperative lower Hb level $(P<0.001)$, prolonged operation time $(P<0.001)$, and increased intraoperative blood loss $(P<0.001)$.
\end{abstract}

Conclusions: Given the high prevalence and potential risk of transfusion in TJA, interventions for identified risk factors should be used during the perioperative period.

Keywords: Total knee arthroplasty, Total hip arthroplasty, Allogenic blood transfusion, Preoperative hemoglobin level

\section{Background}

Total joint arthroplasty (TJA), representing an effective procedure in the treatment of various joint pathologies, is usually associated with substantial blood loss, which increases allogenic blood transfusion requirements during the perioperative period. Previous studies have proved that blood transfusion increased the risk of surgical-site infection, major complications, longer length of hospitalization, and even mortality in total knee and hip arthroplasty (TKA and THA) [1-3]. Additionally,

\footnotetext{
* Correspondence: qingj@nju.edu.cn

${ }^{+}$Kai Song and Pin Pan contributed equally to this research and shared joint first authorship.

${ }^{1}$ Department of Sports Medicine and Adult Reconstructive Surgery, Drum Tower Hospital, School of Medicine, Nanjing University, 321 Zhongshan Road, Nanjing 210008, Jiangsu, People's Republic of China

${ }^{2}$ Laboratory for Bone and Joint Disease, Model Animal Research Center (MARC), Nanjing University, Nanjing 210093, Jiangsu, People's Republic of China
}

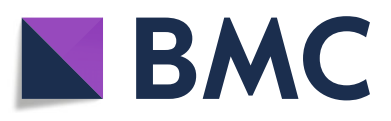

(c) The Author(s). 2019 Open Access This article is distributed under the terms of the Creative Commons Attribution 4.0 International License (http://creativecommons.org/licenses/by/4.0/), which permits unrestricted use, distribution, and reproduction in any medium, provided you give appropriate credit to the original author(s) and the source, provide a link to the Creative Commons license, and indicate if changes were made. The Creative Commons Public Domain Dedication waiver (http://creativecommons.org/publicdomain/zero/1.0/) applies to the data made available in this article, unless otherwise stated.

transfusion causes higher total hospitalization cost and more medical resource use [4].

Therefore, perioperative blood management to avoid allogenic transfusion in TJA has gained increasing attention. Determining the incidence of transfusion and identifying patients at higher risk of transfusion are critical to establishing a strategy to decrease blood loss and transfusion rates. The reported incidence of transfusion varies from 3.5 to $18.5 \%$ in TKA and from 5.4 to $26.2 \%$ in THA, which is negatively associated with hospital procedure volume [5]. Additionally, different blood management strategies also cause the variation of transfusion rates. For orthopedic surgeries, the risk factors for transfusion include advanced age, higher American Society of Anesthesiologists (ASA) grade, lower level of preoperative hemoglobin $(\mathrm{Hb})$, and increased postoperative drainage volume [6]. 
In this retrospective study, we aim to determine the incidence and risk factors for intraoperative and postoperative allogenic blood transfusion in patients undergoing primary unilateral TKA and THA.

\section{Methods}

This retrospective study included consecutive patients undergoing primary unilateral TKA and THA at our institution between January 2010 and July 2014. For patients who received staged TKAs or THAs for both lower limbs during this period, only the first procedure was included. We excluded patients with coagulation disorders or on anticoagulants before surgery. Patients undergoing autologous blood predonation before surgery were also excluded. This study was approved by our institutional review board (IRB).

All surgeries were performed by four surgeons with standard procedure. The medial parapatellar arthrotomy was used in TKA. A pneumatic tourniquet was applied before skin incision and it was released after cementing the prosthesis. THAs were conducted using modified Hardinge approach. A closed drainage system was employed routinely in TKA and THA, and it was removed within $48 \mathrm{~h}$ postoperatively. Tranexamic acid and other hemostatic agents were not used in any of the patients. Recommended thromboprophylaxis, consisting of chemical (rivaroxaban or low-molecular-weight heparin) and mechanical (intermittent pneumatic compression devices) prophylaxis, was used for each patient. All patients underwent a unified rehabilitation program following surgery.

Intraoperatively, the allogenic blood transfusion trigger was a $\mathrm{Hb}$ level of less than $9.0 \mathrm{~g} / \mathrm{dL}$. Postoperatively, patients were transfused if their level of $\mathrm{Hb}$ was less than $8.0 \mathrm{~g} / \mathrm{dL}$, or if they presented with obvious anemic symptoms and the level of $\mathrm{Hb}$ was less than $9.0 \mathrm{~g} / \mathrm{dL}$. All intraoperative and postoperative transfusion events were recorded. We collected patients' demographic information from medical records, including age, gender, body mass index (BMI), coexisting illnesses, smoking history,

Table 1 Patient's demographic, clinical, and surgical characteristics

\begin{tabular}{|c|c|c|c|}
\hline Characteristics & Total $(n=1534)$ & TKA $(n=541)$ & THA $(n=993)$ \\
\hline \multicolumn{4}{|l|}{ Gender } \\
\hline Male (\%) & $467(30.4)$ & $97(17.9)$ & $370(37.3)$ \\
\hline Female (\%) & $1067(69.6)$ & $444(82.1)$ & $623(62.7)$ \\
\hline Age, years (mean $\pm S D$ ) & $64.8 \pm 12.5$ & $67.4 \pm 7.4$ & $63.4 \pm 14.3$ \\
\hline $\mathrm{BMI}, \mathrm{kg} / \mathrm{m}^{2}($ mean $\pm \mathrm{SD})$ & $24.4 \pm 4.0$ & $26.1 \pm 3.8$ & $23.4 \pm 3.8$ \\
\hline Diabetes (\%) & $184(12.0)$ & $89(16.5)$ & $95(9.6)$ \\
\hline Hypertension (\%) & $548(35.7)$ & $239(44.2)$ & $309(31.1)$ \\
\hline Malignance (\%) & $41(2.7)$ & $16(3.0)$ & $25(2.5)$ \\
\hline Smoking (\%) & $160(10.4)$ & $32(5.9)$ & $128(12.9)$ \\
\hline \multicolumn{4}{|l|}{ Diagnosis } \\
\hline $\mathrm{OA}(\%)$ & $643(41.9)$ & $491(90.8)$ & $152(15.3)$ \\
\hline RA (\%) & $64(4.2)$ & $50(9.2)$ & $14(1.4)$ \\
\hline Femoral neck fracture (\%) & $401(26.1)$ & - & $401(40.4)$ \\
\hline ONFH (\%) & $255(16.6)$ & - & $255(25.7)$ \\
\hline $\mathrm{DDH}(\%)$ & $106(6.9)$ & - & $106(10.7)$ \\
\hline AS (\%) & $54(3.5)$ & - & $54(5.4)$ \\
\hline Previous septic arthritis (\%) & $11(0.7)$ & - & $11(1.1)$ \\
\hline $\mathrm{PT}, \mathrm{s}($ mean $\pm \mathrm{SD})$ & $11.5 \pm 1.0$ & $11.4 \pm 0.9$ & $11.6 \pm 1.0$ \\
\hline INR (mean $\pm \mathrm{SD})$ & $1.01 \pm 0.09$ & $1.00 \pm 0.08$ & $1.02 \pm 0.09$ \\
\hline $\mathrm{APTT}, \mathrm{s}$ (mean $\pm \mathrm{SD})$ & $26.9 \pm 4.5$ & $25.9 \pm 3.8$ & $27.4 \pm 4.8$ \\
\hline Preoperative Hb level, g/L (mean \pm SD) & $127.9 \pm 14.9$ & $127.3 \pm 13.8$ & $128.2 \pm 15.5$ \\
\hline $\mathrm{PLT}, 10^{9} / \mathrm{L}($ mean $\pm \mathrm{SD})$ & $200.4 \pm 64.3$ & $206.7 \pm 66.9$ & $197.0 \pm 62.6$ \\
\hline Operation time, min (mean \pm SD) & $110.3 \pm 29.8$ & $124.2 \pm 23.1$ & $102.7 \pm 30.4$ \\
\hline Intraoperative blood loss, mL (mean \pm SD) & $290.2 \pm 168.9$ & $201.3 \pm 111.0$ & $338.7 \pm 175.2$ \\
\hline
\end{tabular}

TKA total knee arthroplasty, THA total hip arthroplasty, SD standard deviation, $B M I$ body mass index, OA osteoarthritis, RA rheumatoid arthritis, ONFH osteonecrosis of the femur head, $D D H$ developmental dysplasia of the hip, $A S$ ankylosing spondylitis, $P T$ prothrombin time, INR international normalized ratio, APTT activated partial thromboplastin time, $\mathrm{Hb}$ hemoglobin, PLT platelet count 
and primary diagnosis. The preoperative laboratory values, including $\mathrm{Hb}$, platelet count (PLT), plasma prothrombin time $(\mathrm{PT})$, international normalized ratio (INR), and activated partial thromboplastin time (APTT), were also collected. We obtained the operation time and estimated intraoperative blood loss from operation notes.

Statistical analysis was conducted using STATA version 12.0 (Stata Corp. LP, College Station, TX, USA). Variables, including age, gender, BMI, diabetes, hypertension, malignancy, smoking history, diagnosis, PT, INR, APTT, Hb, PLT, operation time, and intraoperative blood loss, were compared between transfusion group and non-transfusion group. Qualitative variables were analyzed using the chi-square test, and quantitative variables were analyzed using $t$ test. Subsequently, factors with $P$ value less than 0.05 were introduced into the multivariate logistic regression analysis to identify the independent risk factors for transfusion. A $P$ value less than 0.05 was considered statistically significant.

\section{Results}

A total of 1534 patients were enrolled in this study. There were 1067 females and 467 males, with a mean age of $64.8 \pm 12.5$ years (range 17-93 years). There were 541 patients undergoing primary unilateral TKA and 993 patients undergoing primary unilateral THA. Table 1 shows the baseline characteristics of the study population.

Two hundred and 74 patients (17.9\%) received allogenic blood transfusion. Among them, 121 patients
(7.9\%) were transfused during the surgery and 174 patients (11.3\%) were transfused after surgery. In the TKA group, the incidence of postoperative transfusion (13.9\%, $n=75)$ was higher than that $(10.0 \%, n=99)$ in the THA group $(P=0.022)$. There was no statistical difference between TKA group and THA group in intraoperative transfusion $(7.0 \%$ vs. $8.4 \%, P=0.345)$ and total transfusion $(19.4 \%$ vs. $17.0 \%, P=0.243)$.

According to the univariate analysis for TKA group, gender $(P=0.027)$, preoperative level of $\mathrm{Hb}(P<0.001)$, and intraoperative blood loss $(P<0.001)$ were associated with total transfusion (Table 2). The subsequent multivariate logistic regression analysis showed that preoperative lower level of $\mathrm{Hb}(P<0.001)$ and increased amount of intraoperative blood loss $(P<0.001)$ were the independent risk factors for total transfusion in TKA (Table 3). Likewise, we found that prolonged APTT $(P=0.035)$, preoperative lower level of $\mathrm{Hb}(P=0.007)$, and increased blood loss $(P<0.001)$ were independent predictors for intraoperative transfusion in TKA. Female $(P=0.027)$ and preoperative lower $\mathrm{Hb}$ level $(P<0.001)$ were the independent predictors for postoperative transfusion in TKA.

In THA group, gender $(P<0.001)$, diagnosis $(P=$ 0.019), preoperative $\mathrm{Hb}$ level $(P<0.001)$, operation time $(P<0.001)$, and intraoperative blood loss $(P<0.001)$ were found to be associated with total transfusion by univariate analysis (Table 4). Subsequently, multivariate logistic regression analysis showed that female $(P=$ $0.023)$, preoperative lower $\mathrm{Hb}$ level $(P<0.001)$, prolonged operation time $(P<0.001)$, and increased intraoperative blood loss $(P<0.001)$ were the independent

Table 2 Univariate analysis of the risk factors for transfusion in TKA

\begin{tabular}{|c|c|c|c|}
\hline Variable & Non-transfusion $(n=436)$ & Transfusion $(n=105)$ & $P$ value \\
\hline Female gender (\%) & $350(80.3)$ & $94(89.5)$ & $0.027^{*}$ \\
\hline Age, years (mean $\pm \mathrm{SD}$ ) & $67.5(7.2)$ & $66.6(8.5)$ & 0.264 \\
\hline $\mathrm{BMl}, \mathrm{kg} / \mathrm{m}^{2}$ (mean $\left.\pm \mathrm{SD}\right)$ & $26.1(3.7)$ & $26.2(4.3)$ & 0.762 \\
\hline Diabetes (\%) & $69(15.8)$ & $20(19.1)$ & 0.424 \\
\hline Hypertension (\%) & $198(45.4)$ & $41(39.1)$ & 0.238 \\
\hline Malignance (\%) & $12(2.8)$ & $4(3.8)$ & 0.566 \\
\hline Smoking (\%) & $28(6.4)$ & $4(3.8)$ & 0.308 \\
\hline Diagnosis of RA (\%) & $36(8.3)$ & $14(13.3)$ & 0.107 \\
\hline $\mathrm{PT}, \mathrm{s}($ mean $\pm \mathrm{SD})$ & $11.4(0.9)$ & $11.5(0.8)$ & 0.189 \\
\hline INR (mean $\pm \mathrm{SD}$ ) & $0.99(0.08)$ & $1.01(0.07)$ & 0.192 \\
\hline APTT, s (mean \pm SD) & $25.8(3.9)$ & $26.5(3.7)$ & 0.076 \\
\hline Preoperative $\mathrm{Hb}$ level, g/L (mean \pm SD) & $128.8(13.2)$ & $121.1(14.5)$ & $<0.001^{*}$ \\
\hline $\mathrm{PLT}, 10^{9} / \mathrm{L}($ mean $\pm \mathrm{SD})$ & $207.3(65.3)$ & $204.1(73.5)$ & 0.657 \\
\hline Operation time, min (mean \pm SD) & $124.1(22.7)$ & $124.6(24.5)$ & 0.822 \\
\hline Intraoperative blood loss, $\mathrm{mL}$ (mean \pm SD) & $189.4(95.5)$ & $250.4(151.0)$ & $<0.001^{*}$ \\
\hline
\end{tabular}

$S D$ standard deviation, $B M I$ body mass index, RA rheumatoid arthritis, $P T$ prothrombin time, INR international normalized ratio, APTT activated partial thromboplastin time, $\mathrm{Hb}$ hemoglobin, $P L T$ platelet count

${ }^{*} P<0.05$ was considered statistically significant 
Table 3 Multivariate logistic regression analysis to identify independent risk factors for transfusion in TKA

\begin{tabular}{llll}
\hline & OR & $95 \% \mathrm{Cl}$ & $P$ value \\
\hline Female & 1.545 & $0.750-3.182$ & 0.238 \\
Preoperative hemoglobin level & 0.959 & $0.942-0.977$ & $<0.001^{*}$ \\
Intraoperative blood loss & 1.005 & $1.003-1.007$ & $<0.001^{*}$
\end{tabular}

$O R$ odds ratio, $\mathrm{Cl}$ confidence interval

${ }^{*} P<0.05$ was considered statistically significant

risk factors for total transfusion (Table 5). For intraoperative transfusion in THA, preoperative lower $\mathrm{Hb}$ level $(P<0.001)$, prolonged operation time $(P<0.001)$, and increased intraoperative blood loss $(P<0.001)$ were the independent predictors. For postoperative transfusion in THA, female $(P=0.037)$, preoperative lower level of $\mathrm{Hb}(P=0.007)$, and increased blood loss $(P<0.001)$ were the independent predictors.

\section{Discussion}

The incidence of transfusion in TJA, TKA, and THA was $17.9 \%, 19.4 \%$, and $17.0 \%$, respectively. In TKA, preoperative lower level of $\mathrm{Hb}$ and increased amount of intraoperative blood loss were significantly associated with transfusion. In THA, female, preoperative lower $\mathrm{Hb}$ level, prolonged operation time, and increased intraoperative blood loss were the independent risk factors for transfusion. Preoperative optimization and preventive measures for these risk factors may be able to decrease transfusion rates.

Total joint arthroplasty is usually associated with excessive blood loss, which may cause a mean $\mathrm{Hb}$ decrease of $3.7 \mathrm{~g} / \mathrm{dL}$ [7] and requirements for allogenic transfusion. Because of different patient and hospital characteristics, the reported incidence of transfusion varies widely from 2.5 to $35.3 \%$ in TKA and from 14 to $29.8 \%$ in THA $[5,8-12]$. Studies about the trends in allogenic transfusion reveal a decline in TKA and an increase in THA $[9,13]$. Transfusion is found to be dose-dependently associated with surgical site infection following TJA $[3,14]$. It also increases the risk of postoperative cardiac arrhythmia, confusion, and urinary catheterization [15]. Patients receiving transfusion during TJA are prone to higher cost, prolonged length of stay, and discharge to short-term care [13]. Moreover, transfusion appears to

Table 4 Univariate analysis of the risk factors for transfusion in THA

\begin{tabular}{|c|c|c|c|}
\hline Variable & Non-transfusion $(n=824)$ & Transfusion $(n=169)$ & $P$ value \\
\hline Female gender (\%) & $491(59.6)$ & $132(78.1)$ & $<0.001^{*}$ \\
\hline Age, years (mean $\pm S D)$ & $63.7(14.1)$ & $61.9(15.2)$ & 0.142 \\
\hline $\mathrm{BMI}, \mathrm{kg} / \mathrm{m}^{2}($ mean $\pm \mathrm{SD})$ & $23.4(3.7)$ & $23.6(3.9)$ & 0.518 \\
\hline Diabetes (\%) & $78(9.5)$ & $17(10.1)$ & 0.811 \\
\hline Hypertension (\%) & $250(30.3)$ & $59(34.9)$ & 0.242 \\
\hline Malignance (\%) & $22(2.7)$ & $3(1.8)$ & 0.499 \\
\hline Smoking (\%) & $107(13.0)$ & $21(12.4)$ & 0.843 \\
\hline Diagnosis & & & $0.019^{*}$ \\
\hline $\mathrm{OA}(\%)$ & $119(14.4)$ & $33(19.5)$ & \\
\hline RA (\%) & $8(1.0)$ & $6(3.6)$ & \\
\hline Femoral neck fracture (\%) & $346(42.0)$ & $55(32.5)$ & \\
\hline ONFH (\%) & $216(26.2)$ & $39(23.1)$ & \\
\hline $\mathrm{DDH}(\%)$ & $83(10.1)$ & $23(13.6)$ & \\
\hline AS (\%) & $44(5.3)$ & $10(5.9)$ & \\
\hline Previous septic arthritis (\%) & $8(1.0)$ & $3(1.8)$ & \\
\hline PT, s (mean $\pm \mathrm{SD})$ & $11.6(1.0)$ & $11.7(1.1)$ & 0.177 \\
\hline INR (mean \pm SD) & $1.02(0.09)$ & $1.03(0.11)$ & 0.146 \\
\hline APTT, s (mean \pm SD) & $27.4(4.9)$ & $27.5(4.1)$ & 0.698 \\
\hline Preoperative $\mathrm{Hb}$ level, g/L (mean \pm SD) & $130.1(15.1)$ & $119.1(14.4)$ & $<0.001^{*}$ \\
\hline $\mathrm{PLT}, 10^{9} / \mathrm{L}($ mean $\pm \mathrm{SD})$ & $197.8(62.5)$ & $193.0(63.0)$ & 0.361 \\
\hline Operation time, min (mean \pm SD) & $99.6(28.0)$ & $117.9(36.4)$ & $<0.001^{*}$ \\
\hline Intraoperative blood loss, mL (mean \pm SD) & $314.6(163.5)$ & $456.0(183.3)$ & $<0.001^{*}$ \\
\hline
\end{tabular}


Table 5 Multivariate logistic regression analysis to identify independent risk factors for transfusion in THA

\begin{tabular}{llll}
\hline & OR & $95 \% \mathrm{Cl}$ & $P$ value \\
\hline Female & 1.694 & $1.074-2.674$ & $0.023^{*}$ \\
Diagnosis & 1.041 & $0.917-1.182$ & 0.533 \\
Preoperative hemoglobin level & 0.948 & $0.934-0.961$ & $<0.001^{*}$ \\
Operation time & 1.015 & $1.009-1.021$ & $<0.001^{*}$ \\
Intraoperative blood loss & 1.004 & $1.003-1.005$ & $<0.001^{*}$ \\
\hline
\end{tabular}

$O R$ odds ratio, $\mathrm{Cl}$ confidence interval

${ }^{*} P<0.05$ was considered statistically significant

increase the rates of in-hospital and 1-year postoperative mortality in TJA $[15,16]$.

Preoperative $\mathrm{Hb}$ level is considered a significant predictor for transfusion following TJA [11, 17, 18], which is consistent with the present study. Patients with a preoperative $\mathrm{Hb}$ level less than $13 \mathrm{~g} / \mathrm{dL}$ are at a fourfold higher risk of having transfusion compared to those with $\mathrm{Hb}$ level of $>13 \mathrm{~g} / \mathrm{dL}$ [18]. Bleeding and clotting disorders are also independent risk factors for transfusion [14], and we excluded patients with these comorbidities from our study. According to previous studies, female and older age have proven to be associated with transfusion in TKA and THA $[8,19,20]$. In our study, female is found to be the independent risk factor for postoperative transfusion but not total or intraoperative transfusion in TKA; it is the independent risk factor for total and postoperative transfusion but not intraoperative transfusion in THA. We did not find the relationship between age and transfusion rates.

There are several limitations in our study. First, this study has all limitations inherent to retrospective observational studies, which should be noted when interpreting the results. Second, we only recorded the events of transfusion during hospitalization. Some patients may receive transfusion after discharge to another hospital for short-term inpatient care. Third, postoperative parameters (drainage volume, anticoagulants use, etc.) and other confounders (ASA grade, comorbidity index, etc.) may also influence transfusion rates, but we did not include these factors into the analysis. Fourth, the value of intraoperative blood loss was estimated by the volume of blood in the suction canister plus the amount of blood in the dry sponges, which may cause the inaccuracy of the data. It also should be noted that the prevalence of transfusion in this study may be higher, because we did not optimize preoperative $\mathrm{Hb}$ concentration or use tranexamic acid during the research period.

Given the high incidence of transfusion in TJA, further research to decrease blood loss and optimize blood management is warranted. For patients with identified risk factors, perioperative interventions should be employed to reduce the transfusion rates.

\section{Abbreviations}

APTT: Activated partial thromboplastin time; ASA: American Society of Anesthesiologists; BMI: Body mass index; Hb: Hemoglobin; INR: International normalized ratio; IRB: Institutional review board; PLT: Platelet count; PT: Plasma prothrombin time; THA: Total hip arthroplasty; TJA: Total joint arthroplasty; TKA: Total knee arthroplasty

\section{Acknowledgements \\ This work was supported by Jiangsu Provincial Key Research and Development Foundation (BE2016608), National Science Foundation of China (81702151), Natural Science Foundation of Jiangsu Provincel (BK20170121), and Fundamental Research Funds for the Central Universities (021414380306).}

\section{Authors' contributions}

QJ contributed substantially to the conception and design of the study. KS, YY, PP, and TJ collected and analyzed the data. KS wrote the manuscript with support from PP. All authors read and approved the final manuscript.

\section{Funding}

This work was supported by Jiangsu Provincial Key Research and Development Foundation (BE2016608), National Science Foundation of China (81702151), Natural Science Foundation of Jiangsu Province (BK20170121), and Fundamental Research Funds for the Central Universities (021414380306).

\section{Availability of data and materials}

The data used to support the findings of this study are available from the corresponding author upon request.

\section{Ethics approval and consent to participate}

This study was approved by the institutional review board (IRB) of Nanjing Drum Tower Hospital (No. 2012029).

\section{Consent for publication}

Not applicable

\section{Competing interests}

The authors declare that they have no competing interests

Received: 27 July 2019 Accepted: 18 August 2019

Published online: 28 August 2019

\section{References}

1. Danninger T, Rasul R, Poeran J, Stundner O, Mazumdar M, Fleischut PM, Poultsides L, Memtsoudis SG. Blood transfusions in total hip and knee arthroplasty: an analysis of outcomes. ScientificWorld Journal. 2014;2014: 623460. https://doi.org/10.1155/2014/623460.

2. Hart A, Khalil JA, Carli A, Huk O, Zukor D, Antoniou J. Blood transfusion in primary total hip and knee arthroplasty. Incidence, risk factors, and thirtyday complication rates. J Bone Joint Surg Am. 2014;96(23):1945-51. https:// doi.org/10.2106/JBJS.N.00077.

3. Kim JL, Park JH, Han SB, Cho IY, Jang KM. Allogeneic blood transfusion is a significant risk factor for surgical-site infection following total hip and knee arthroplasty: a meta-analysis. J Arthroplasty. 2017;32(1):320-5. https://doi. org/10.1016/j.arth.2016.08.026.

4. Nichols $\mathrm{Cl}$, Vose JG. Comparative risk of transfusion and incremental total hospitalization cost for primary unilateral, bilateral, and revision total knee arthroplasty procedures. J Arthroplasty. 2016;31(3):583-589 e581. https://doi. org/10.1016/j.arth.2015.10.013.

5. Menendez ME, Lu N, Huybrechts KF, Ring D, Barnes CL, Ladha K, Bateman BT. Variation in use of blood transfusion in primary total hip and knee arthroplasties. J Arthroplasty. 2016;31(12):2757-63 e2752. https://doi.org/10.1 016/j.arth.2016.05.022.

6. Tang JH, Lyu Y, Cheng LM, Li YC, Gou DM. Risk factors for the postoperative transfusion of allogeneic blood in orthopedics patients with intraoperative blood salvage: a retrospective cohort study. Medicine. 2016;95(8):e2866. https://doi.org/10.1097/MD.0000000000002866.

7. Boutsiadis A, Reynolds RJ, Saffarini M, Panisset JC. Factors that influence blood loss and need for transfusion following total knee arthroplasty. Ann Transl Med. 2017;5(21):418. https://doi.org/10.21037/atm.2017.08.11. 
8. Slover J, Lavery JA, Schwarzkopf R, lorio R, Bosco J, Gold HT. Incidence and risk factors for blood transfusion in total joint arthroplasty: analysis of a statewide database. J Arthroplasty. 2017;32(9):2684-7 e2681. https://doi. org/10.1016/..arth.2017.04.048.

9. Helder CW, Schwartz BE, Redondo M, Piponov HI, Gonzalez MH. Blood transfusion after primary total hip arthroplasty: national trends and perioperative outcomes. J Surg Orthop Adv. 2017;26(4):216-22.

10. Al-Turki AA, Al-Araifi AK, Badakhan BA, Al-Nazzawi MT, Alghnam S, Al-Turki AS. Predictors of blood transfusion following total knee replacement at a tertiary care center in Central Saudi Arabia. Saudi Med J. 2017;38(6):598-603. https://doi.org/10.15537/smj.2017.6.17475.

11. Yeh JZ, Chen JY, Bin Abd Razak HR, Loh BH, Hao Y, Yew AK, Chia SL, Lo NN, Yeo SJ. Preoperative haemoglobin cut-off values for the prediction of postoperative transfusion in total knee arthroplasty. Knee Surg Sports Traumatol Arthrosc. 2016;24(10):3293-8. https://doi.org/10.1007/s00167-016-4183-1.

12. Noticewala MS, Nyce JD, Wang W, Geller JA, Macaulay W. Predicting need for allogeneic transfusion after total knee arthroplasty. J Arthroplasty. 2012; 27(6):961-7. https://doi.org/10.1016/j.arth.2011.10.008.

13. Mistry JB, Gwam CU, Naziri Q, Pivec R, Abraham R, Mont MA, Delanois RE. Are allogeneic transfusions decreasing in total knee arthroplasty patients? National Inpatient Sample 2009-2013. J Arthroplasty. 2018;33(6):1705-12. https://doi.org/10.1016/j.arth.2017.12.014.

14. Everhart JS, Sojka JH, Mayerson JL, Glassman AH, Scharschmidt TJ. Perioperative allogeneic red blood-cell transfusion associated with surgical site infection after total hip and knee arthroplasty. J Bone Joint Surg Am. 2018:100(4):288-94. https://doi.org/10.2106/JBJS.17.00237.

15. Maempel JF, Wickramasinghe NR, Clement ND, Brenkel IJ, Walmsley PJ. The pre-operative levels of haemoglobin in the blood can be used to predict the risk of allogenic blood transfusion after total knee arthroplasty. Bone Joint J. 2016;98-B(4):490-7. https://doi.org/10.1302/0301-620X.98B4.36245.

16. Browne JA, Adib F, Brown TE, Novicoff WM. Transfusion rates are increasing following total hip arthroplasty: risk factors and outcomes. J Arthroplasty. 2013;28(8 Suppl):34-7. https://doi.org/10.1016/j.arth.2013.03.035.

17. Trevisan C, Klumpp R, Auriemma L, Compagnoni R. An algorithm for predicting blood loss and transfusion risk after total hip arthroplasty. Transfus Apher Sci. 2018. https://doi.org/10.1016/j.transci.2018.03.006.

18. Salido JA, Marin LA, Gomez LA, Zorrilla P, Martinez C. Preoperative hemoglobin levels and the need for transfusion after prosthetic hip and knee surgery: analysis of predictive factors. J Bone Joint Surg Am. 2002;84-A(2):216-20

19. To J, Sinha R, Kim SW, Robinson K, Kearney B, Howie D, To LB. Predicting perioperative transfusion in elective hip and knee arthroplasty: a validated predictive model. Anesthesiology. 2017;127(2):317-25. https://doi.org/10.1 097/ALN.0000000000001709.

20. Sizer SC, Cherian JJ, Elmallah RD, Pierce TP, Beaver WB, Mont MA. Predicting blood loss in total knee and hip arthroplasty. Orthop Clin North Am. 2015; 46(4):445-59. https://doi.org/10.1016/j.ocl.2015.06.002.

\section{Publisher's Note}

Springer Nature remains neutral with regard to jurisdictional claims in published maps and institutional affiliations.

\section{Ready to submit your research? Choose BMC and benefit from}

- fast, convenient online submission

- thorough peer review by experienced researchers in your field

- rapid publication on acceptance

- support for research data, including large and complex data types

- gold Open Access which fosters wider collaboration and increased citations

- maximum visibility for your research: over $100 \mathrm{M}$ website views per year

At BMC, research is always in progress.

Learn more biomedcentral.com/submissions 